\title{
Practice of diagnostic hysteroscopy after myomectomy in the prevention of intrauterine adhesions: experience of Ouakam military hospital (Dakar, Senegal)
}

\author{
Marie Edouard Faye Dieme ${ }^{1,2 *}$, Mouhamadou Mansour Niang ${ }^{1,2}$, Omar Gassama ${ }^{1}$, Abdoul \\ Aziz Diouf ${ }^{1,3}$, Marietou Thiam Coulibaly ${ }^{1,4}$, Alassane Diouf ${ }^{1,3}$, Jean Charles Moreau ${ }^{1}$
}

\author{
${ }^{1}$ Gynecological and Obstetrical Clinic, Le Dantec Teaching Hospital, Cheikh Anta Diop University, Dakar, Senegal \\ ${ }^{2}$ Ouakam Military Hospital, Dakar, Senegal \\ ${ }^{3}$ Pikine National Health Center, Dakar, Senegal \\ ${ }^{4}$ Thies University, Faculty of Health Sciences, Thies, Senegal
}

Received: 24 February 2018

Accepted: 28 March 2018

\section{*Correspondence: \\ Dr. Marie Edouard Faye Dieme, \\ E-mail: mefdieme@yahoo.fr}

Copyright: (C) the author(s), publisher and licensee Medip Academy. This is an open-access article distributed under the terms of the Creative Commons Attribution Non-Commercial License, which permits unrestricted non-commercial use, distribution, and reproduction in any medium, provided the original work is properly cited.

\begin{abstract}
Background: Surgical treatment of myomas may be the cause of some complications, including intrauterine adhesions. The objective of the study was to evaluate the incidence of intrauterine adhesions in patients who underwent myomectomy by laparotomy or hysteroscopic resection.

Methods: We carried out a prospective single center study from August $1^{\text {st }} 2016$ to May $31^{\text {st }} 2017$ in the gynaecological and obstetrical department of Ouakam the Military Hospital (Senegal). We included patients who underwent myomectomy by laparotomy with opening of the uterine cavity or myomectomy by hysteroscopy. A diagnostic hysteroscopy was performed to search post-operative intrauterine adhesions. For each patient, we studied the socio-demographic aspects, the surgical approach, the delay of diagnostic hysteroscopy, the appearance of uterine cavity and the tolerance of hysteroscopy.

Results: 54 patients underwent the diagnostic hysteroscopy. The mean age was 36 years old. The main indication of myomectomy was menorrhagia. 37 patients underwent myomectomy by laparotomy and 17 by hysteroscopy. Each case was followed by a post-operative diagnostic hysteroscopy with a mean delay time of 58 days. We found postoperative intrauterine adhesions in 7 patients ( 5 in the laparotomy group and 2 in hysteroscopy group).

Conclusions: Early diagnostic hysteroscopy after myomectomy should be done in our context to reduce postoperative intrauterine adhesions and preserve the patient's fertility.
\end{abstract}

Keywords: Diagnostic hysteroscopic, Intrauterine adhesions, Synechiae, Senegal myomectomy, Uterine myomas

\section{INTRODUCTION}

Uterine myomas are benign tumors developed at the expense of the uterine muscle. Their incidence in the population of women in reproductive age is estimated between 20 and $50 \% .1$ This incidence increases with age and varies by ethnicity. This pathology, often asymptomatic, is more common in African women. ${ }^{1}$
When it is symptomatic (menorrhagia, pelvic chronic pain, infertility, signs of bladder and/or rectal compression), its management sometimes requires surgery, which was usually performed by laparotomy.

With the advent of minimally invasive surgery, hysteroscopy has become essential in the management of this pathology, particularly for intracavitary myomas 
(types 0, 1 and 2 less than or equal to $4 \mathrm{~cm}$ ). Hysteroscopic resection of submucosal myomas, even asymptomatic, is recommended in patients with a desire for pregnancy. ${ }^{2}$

Hysteroscopic surgery has been a long time inaccessible in our practice. The strengthening of surgeons through internships abroad, the local organization of several workshops facilitated by international experts and the acquisition of endoscopy equipment have made it possible to develop this practice and facilitate patients' access to minimally invasive surgery.

However, the treatment of myomas, whether carried out by abdominal myomectomy or by hysteroscopy, may be the cause of some complications, including intrauterine adhesions. These may be increase the risk of infertility, miscarriages, complications during pregnancy, dysmenorrhea, menstrual cycle disorders and chronic pelvic pain. ${ }^{3}$

Diagnostic hysteroscopy is recommended after myomectomy with the aim of evaluating the occurrence of intrauterine adhesions. ${ }^{4}$

The objective of this study was to evaluate the incidence of post-operative uterine synechiae in patients who had undergone abdominal or hysteroscopic myomectomy at Ouakam Military Hospital in Dakar, Senegal.

\section{METHODS}

It was a prospective and descriptive study conducted over a period of 10 months, from August 1st 2016 to May 31st 2017 in the Gynaecological and Obstetrical department of Ouakam Military Hospital (Dakar, Senegal).

Our study involved patients who had benefited from myomectomy performed either by laparotomy or hysteroscopic surgery. Were Included in the study those whose operative report revealed a notion of scarring of the uterine mucosa (accidental opening of the uterine cavity during enucleation of a myoma) or who had benefited from hysteroscopic resection of myomas. Informed consent of patients was systematically obtained. We excluded all cases of myomectomy in which an intrauterine device was placed at the end of the procedure or in which the postoperative follow-up was complicated. We also excluded two virgin patients who had refused vaginoscopy.

All the outpatient diagnostic hysteroscopy were performed with a rigid hysteroscope (Karl Storz). The diameter of the optics $\left(30^{\circ}\right)$ is $2.9 \mathrm{~mm}$ and the sheath diameter is $4 \mathrm{~mm}$ (Figure 1). Complementary equipment included physiological serum packaged in $500 \mathrm{ml}$ bags, sterile Collin speculum, sterile compress, antiseptic, Pozzi's forceps, candles of different sizes, sterile gloves and sterile fields. The diagnostic hysteroscopy was scheduled in the first phase of the cycle (J7-J14), without premedication with misoprostol and antibiotic prophylaxis.

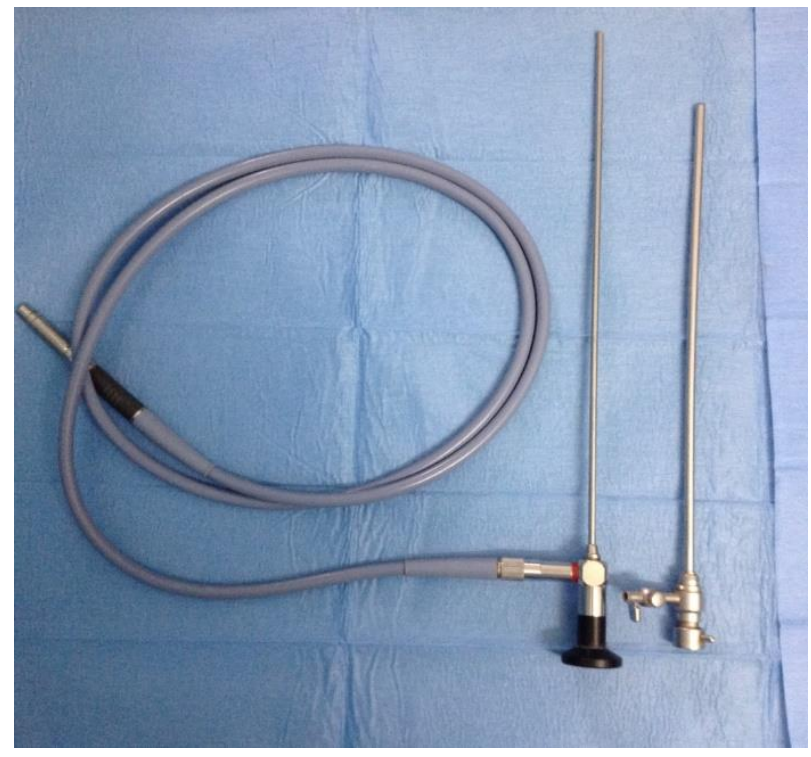

Figure 1: Optics and sheath for diagnostic hysteroscopy (Ouakam Military Hospital's picture).

Any local anesthesia was done. The uterine cavity was distended with normal saline solution using a gravitational system. The saline bag was positioned 120 $\mathrm{cm}$ above the patient. Fluid balance was recorded by measuring the infused and drained fluid using a graduated collection bag.

Each hysteroscopic examination included a vaginoscopy, an examination of the external cervical orifice, a cervicoisthmic time, a detailed study of the uterine cavity, its mucosa and tubal ostia. In the case of visualization of intrauterine adhesions, its location and consistency were evaluated. We used the classification of the European Society of Gynecological Endoscopy (ESGE) to assess the grade of synechiae. An analogue visual scale allowed us to assess the intensity of the pain experienced by the patient during the examination.

For each patient, the following parameters was evaluated: age, parity, predominant symptomatology of myomas, topographic type of myomas according to the FIGO classification (2011), surgical approach, the mean delay time between surgery and diagnostic hysteroscopy and the results of the evaluation of the uterine cavity. The side effects and complications, when they occured, were also notified. Data analysis was performed using SPSS software (version 11.0).

\section{RESULTS}

During the study period, 54 patients underwent diagnostic hysteroscopy after myomectomy. The mean age of patients was 36 years old (range: 26 and 47 years old). 
The majority $(64.8 \%)$ were under 40 years old and $78 \%$ of them were married. In term of gynaecological and obstetrical histories, the rate of nulliparous was $50 \%$ (Table 1). Infertility was noted in $27.8 \%$ of cases.

Table 1: Patients characteristics.

\begin{tabular}{|lll|}
\hline $\begin{array}{l}\text { Characteristics } \\
\text { No. of pregnancies }\end{array}$ & Number $(\mathbf{n}=\mathbf{5 4})$ & Percentage \\
\hline 0 & 19 & 35.2 \\
\hline 1 & 20 & 37 \\
\hline $2-3$ & 10 & 18.5 \\
\hline$\geq 4$ & 5 & 9.3 \\
\hline Parity & & \\
\hline 0 & 27 & 50 \\
\hline 1 & 16 & 29.6 \\
\hline $2-3$ & 8 & 14.8 \\
\hline$\geq 4$ & 3 & 5.6 \\
\hline Fertility & & \\
\hline Normal & 37 & 68.5 \\
\hline Primary infertility & 12 & 22.2 \\
\hline Secondary infertility & 5 & 9,3 \\
\hline
\end{tabular}

The clinical signs that motivated the consultation and subsequent diagnosis of uterine myomas are reported in Table 2. The majority of patients (55.6\%) had menorrhagia. No patients had reported signs of urinary or rectal compression.

Table 2: Symptoms of uterine myomas.

\begin{tabular}{|ll|l|}
\hline Symptoms & $\begin{array}{l}\text { Number } \\
(\mathbf{n}=54)\end{array}$ & Percentage \\
\hline Menorrhagia & 25 & 46.3 \\
\hline Chronic pelvic pain & 11 & 20.4 \\
\hline Menometrorrhagia & 7 & 13 \\
\hline $\begin{array}{l}\text { Menorrhagia with } \\
\text { chronic pelvic pain }\end{array}$ & 4 & 7.4 \\
\hline Infertility & 3 & 5.6 \\
\hline Spaniomenorrhea & 1 & 1.8 \\
\hline Anemia & 1 & 1.8 \\
\hline Hypermenorrhea & 1 & 1.8 \\
\hline Oligomenorrhea & 1 & 1.8 \\
\hline
\end{tabular}

The average duration of symptomatology was 33 months with extremes (range: 6 and 96 months (8 years)). Diagnosis of uterine myomas was made after pelvic ultrasound sometime completed by hysterosonography. It was on the basis of this examination that the topographic classification of myomas was established.

Figure 2 shows the different types of myomas found in our study. The size of the myomas varied between 14 and $130 \mathrm{~mm}$ with an average of $32 \mathrm{~mm}$. It should be noted that the use of diagnostic hysteroscopy was not systematic during the initial exploration of myomas.

Before surgery, 21 patients $(38.9 \%)$ received oral progestogens (Nomegestrol : $42.9 \%$ or Norethisterone :
$57.1 \%$ ). The mean duration of this treatment was 6 months (range: 2 and 24 months). No patients had preoperative treatment with ulipristal acetate or LHRH analogues.

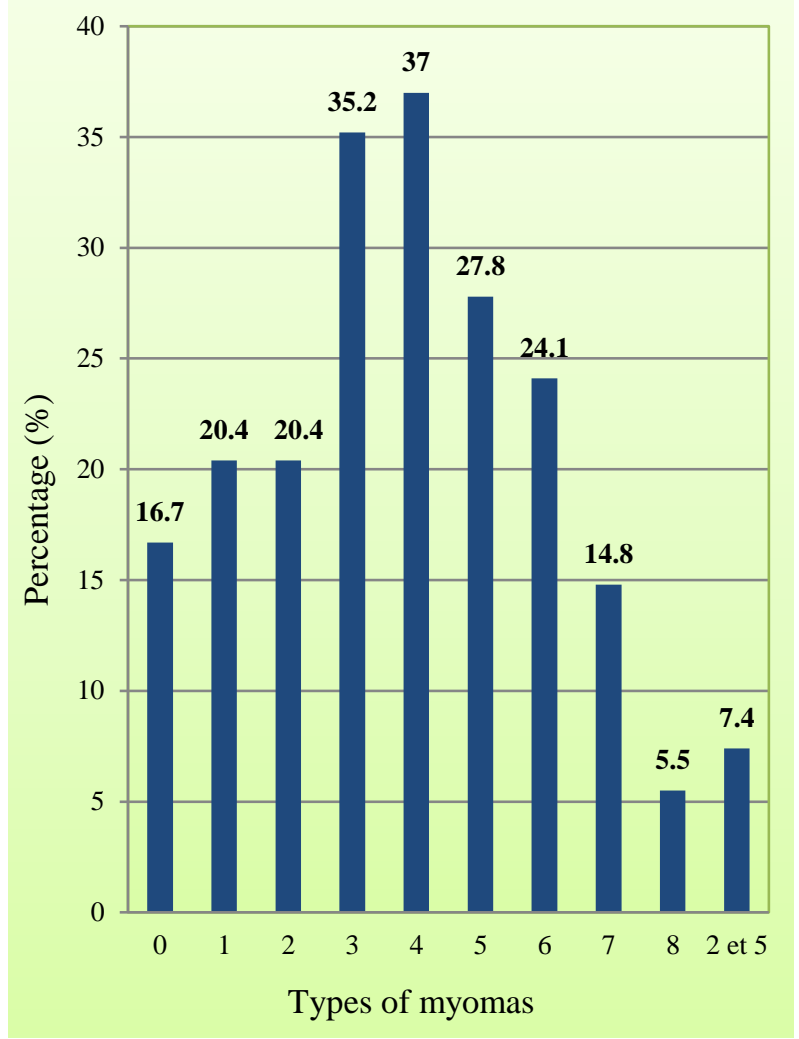

Figure 2: Ultrasound myoma topography (FIGO 2011).

The main indications for myomectomy were menorrhagia $(46.3 \%)$, infertility (31.5\%) and infecondity (27.8\%). Thirty-seven patients $(68.5 \%)$ had abdominal myomectomy with accidental partial opening of the uterine cavity. Seventeen patients $(31.5 \%)$ with a myoma type 0,1 or 2 on ultrasound underwent myomectomy by hysteroscopy.

These hysteroscopic resections were performed in one time. The distension fluid used was glycocoll with a monopolar resector. The follow-up after myomectomy was uneventful.

Post-operative diagnostic hysteroscopy were performed within a mean delay time of 58 days (range 31 days (4 weeks) and 128 days (18 weeks). Catheterization of the cervix was easy in most cases $(83.3 \%)$. In 9 nulliparous patients $(16.7 \%)$, cervical dilatation was necessary.

The endocervical canal was normal in most patients $(96.3 \%)$. Its appearance was not specified in 2 patients. Intrauterine adhesions was found in 7 patients (13\%) (Figure 3). We noted 2 cases of synechiae among the 17 patients who had hysteroscopic resection of submucosal 
myomas $(11.8 \%)$ and 5 cases after abdominal myomectomy $(13.5 \%)$.

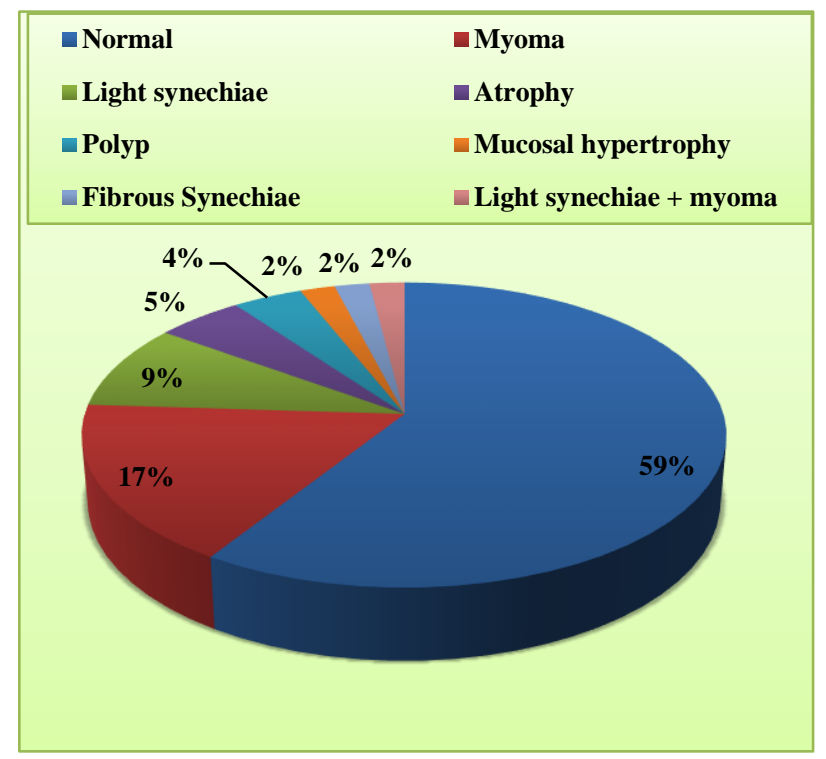

Figure 3: Results of diagnostic control hysteroscopy.

The characteristics of these patients are shown in Table 3. Tubal ostiums was visualized in the majority of cases $(88.9 \%)$. All thin synechiae (stage I) were treated successfully during the procedure. The patient with dense and resistant stage II central mediocavitary synechiae (Figure 4), had an hysteroscopic section 15 days later. The postoperative follow-up was uneventful.

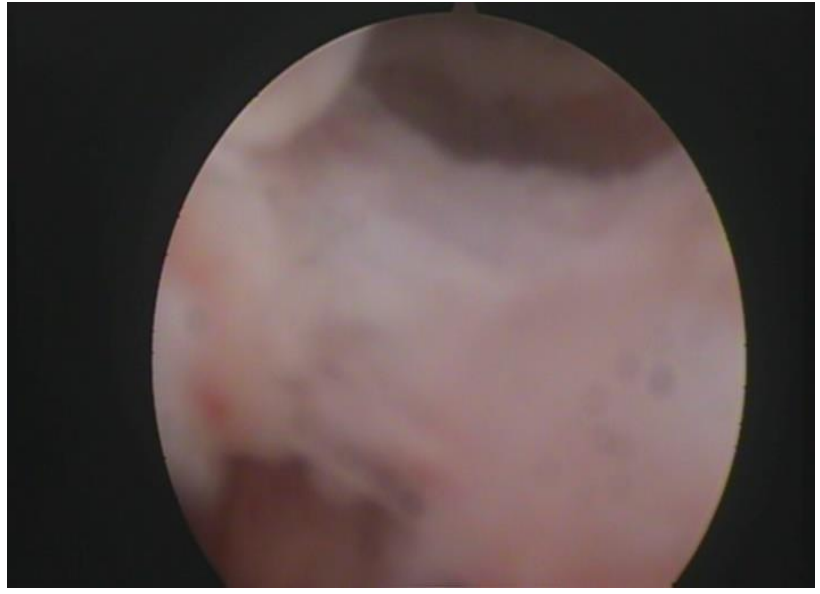

Figure 4: Corporal fibrous synechiae.

This diagnostic control hysteroscopy was found to be painless in most cases. The evaluation of the pain on an analogue visual scale was $4.8 / 10$ on average (range: 2 to $9 / 10$ ). The highest values (6 to 9/10) were found in nulliparous patients.

The procedure did not exceed 20 minutes. The postoperative follow-up was normal in most of the cases $(98.2 \%)$. Only one patient $(1.8 \%)$ presented $38^{\circ} 8$ Celsius fever associated with acute pelvic pain and vomiting. Pelvic ultrasound and electrolytes were normal. This patient recovered after few hours of monitoring and was discharged 24 hours later.

Table 3: Characteristics of patients with intrauterine adhesions.

\begin{tabular}{|c|c|c|c|c|c|c|c|}
\hline Case & $\begin{array}{l}\text { Age } \\
\text { (Years) }\end{array}$ & Parity & History & $\begin{array}{l}\text { Type of } \\
\text { myomectomy }\end{array}$ & $\begin{array}{l}\text { Type and size of } \\
\text { myomas } \\
(\mathrm{mm})\end{array}$ & $\begin{array}{l}\text { Control } \\
\text { hysteroscopy's } \\
\text { delay time } \\
\text { (days) }\end{array}$ & $\begin{array}{l}\text { Type and } \\
\text { topography of } \\
\text { synechiae }\end{array}$ \\
\hline 1 & 27 & 0 & Primary Infertility & laparotomy & $\begin{array}{l}3,4,5,6 \\
45 \text { to } 110 \mathrm{~mm}\end{array}$ & 51 & $\begin{array}{l}\text { Light } \\
\text { Corporal left }\end{array}$ \\
\hline 2 & 33 & 0 & Hypomenorrhea & laparotomy & $\begin{array}{l}2,4,5,7 \\
35 \text { to } 85 \mathrm{~mm}\end{array}$ & 120 & $\begin{array}{l}\text { Fibrous } \\
\text { Corporal central }\end{array}$ \\
\hline 3 & 33 & 0 & 1 miscarriage & hysteroscopy & $\begin{array}{l}1 \text { of } 25 \mathrm{~mm} \\
2 \text { of } 30 \mathrm{~mm}\end{array}$ & 36 & $\begin{array}{l}\text { Light } \\
\text { Corporal right }\end{array}$ \\
\hline 4 & 30 & 0 & Primary infertility & Laparotomy & $\begin{array}{l}3,4,5,6 \\
35 \text { to } 70 \mathrm{~mm}\end{array}$ & 70 & $\begin{array}{l}\text { Light } \\
\text { Corporal left }\end{array}$ \\
\hline 5 & 26 & 1 & No particularities & Laparotomy & $\begin{array}{l}4,5,6 \\
20 \text { to } 100 \mathrm{~mm}\end{array}$ & 43 & $\begin{array}{l}\text { Light } \\
\text { Corporal isthmic } \\
\text { right }\end{array}$ \\
\hline 6 & 31 & 1 & 1 miscarriage & Hystéroscopy & 1 of $30 \mathrm{~mm}$ & 39 & $\begin{array}{l}\text { Light } \\
\text { Cervical isthmic } \\
\text { left }\end{array}$ \\
\hline 7 & 37 & 0 & Hypomenorrhea & Laparotomy & $\begin{array}{l}4,5,6 \\
45 \text { to } 95 \mathrm{~mm}\end{array}$ & 52 & $\begin{array}{l}\text { Light } \\
\text { Corporal fundic } \\
\text { left }\end{array}$ \\
\hline
\end{tabular}




\section{DISCUSSION}

Uterine synechiae are defined as the partial or total adhesion of the uterine walls occurring unphysiologically after an endometrial mucosa damage. ${ }^{5}$ Asherman described this syndrome in $1948 . .^{6}$ One of the most common causes of synechiae was historically tuberculosis, which is still present in some parts of the world. ${ }^{7}$ Currently, the main etiology is surgical trauma, synechiae resulting from ischemia and inflammation secondary to the surgical trauma. The situations most likely to cause intrauterine adhesions are hysteroscopic resections of myomas, polyps, uterine septum and endometrial thermocoagulation. ${ }^{5}$

Other procedures such as biopsy curettage $(1.6 \%)$, abdominal myomectomy (1.3\%) and insertion of an intrauterine device $(0.2 \%)$ are more rarely involved. ${ }^{8}$ These synechiae can be responsible for infertility, miscarriage, pregnancy complications, dysmenorrhea, menstrual cycle disorders and chronic pelvic pain. ${ }^{3}$ Hysteroscopy is currently the gold standard for the diagnosis and treatment of these synechiae. ${ }^{5}$

In our study, myomectomy indications were mainly represented by menorrhagia, infertility and infecondity in respectively $46.3 \%, 31.5 \%$ and $27.8 \%$ of patients. In Munoz study, indications for therapeutic management of endocavital myomas were also represented by menorrhagia $(75-100 \%)$ and infertility $(5-14 \%) .{ }^{9}$

In our practice, despite a better availability of endoscopy equipment, laparotomic myomectomy predominates in the management of uterine myomas (68.5\% of patients). Patients receiving hysteroscopic resection are those with almost exclusively endocavitary myomas. In our context, patients came most of the time with multiple myomas intramural or subserosal (types 4 to 6) associated with type 2 myomas. This situation sometimes requires the enucleation of type 2 myomas by laparotomy with an increased risk of accidental opening of the uterine cavity and endometrial damage.

Our synechiae rate after abdominal myomectomy $(13.5 \%)$ is significantly higher than that reported by other authors, which was $1.3 \% .^{10}$ Only 2 out of 7 patients with uterine synechiae had an endoscopic resection. This confirms the lower morbidity of endo-uterine resection compared to abdominal myomectomy.

Taskin found $37.5 \%$ of intrauterine adhesions after hysteroscopic resection of a single myoma and up to $45 \%$ after resection of multiple myomas. ${ }^{10}$ The rate of synechiae after hysteroscopic resection found in our small series ( 2 cases out of 17 patients or $11.8 \%$ ) remains high compared to the values reported by other authors. ${ }^{11-}$ ${ }^{12}$ In the Fernandez study, it was $9.4 \%$ out of a total of 85 hysteroscopic tests carried out 2 months after resection. ${ }^{12}$
The type of energy we use could explain our results, which is monopolar. In fact, for some teams the use of bipolar device in saline environments provide less postmyomectomy synechiae (7.5\% compared to $31.3 \%) .{ }^{11}$

Without energy use, the incidence of synechiae is much lower with a rate of $4.23 \%$ for Mazzon. ${ }^{13}$

In our series, the synechiae observed were mainly grade I synechiae of the ESGE classification, easily collapsed by the tip of the hysteroscope.

However, the only patient with dense, fibrous synechiae underwent abdominal myomectomy for type 2 myomas and control hysteroscopy was done only after 120 days (16 weeks).

Regarding to the optimal time required to carry out control hysteroscopy, one study showed a significantly higher rate of grade 3 and 4 synechiae in late hysteroscopy ( 8 to 16 weeks) compared with the results recorded after early hysteroscopy ( 2 to 4 weeks). ${ }^{14}$ However, it should be pointed out that the two groups of this retrospective study were not homogeneous in terms of pathologies operated on. Nevertheless, this shows the need for us to adopt the French guidelines which recommend to perform the diagnostic hysteroscopy about 4 weeks after hysteroscopic surgery. ${ }^{15}$

For the prevention of synechiae, no measures have been taken. Several methods have been evaluated by many authors. ${ }^{5,16,17}$ The intrauterine device and the Foley catheter have not been proven to be effective. Most trials on the application of cross-linked pure hyaluronic acid gels after abdomino-pelvic or hysteroscopic gynaecological surgery conclude that intrauterine adhesions incidence and severity are significantly reduced. However, these studies had lack data on subsequent fertility and the French guidelines do not recommend their systematic use. ${ }^{15}$

In addition, the hysteroscopic controls we carried out revealed sub-mucosal myomas that had not been diagnosed during the initial patient evaluation. This shows all the advantages of performing diagnostic hysteroscopy or at least hysterosonography systematically before any myomectomy in order to obtain a precise mapping of the myomatous pathology. However, it stills the problem of virgin patients who, in our socio-cultural context, remain resistant to any endovaginal exploration.

Diagnostic hysteroscopy was relatively well tolerated without any anesthesia or premedication as recommended. ${ }^{15}$ However, we feel it is appropriate to experiment paracervical block in nulliparous patients. In fact, it is this category of patients who were least tolerant to the examination with pain ratings between $6 / 10$ and $9 / 10$. 


\section{CONCLUSION}

Intrauterine adhesions remain one of the most frequent post-operative complications after surgical treatment of submucosal myomas. Their prevention is a major issue to preserve the fertility of patients after the surgery, especially in our countries. Prevention methods are currently limited, and most studies have shown an interest in reducing the rate and severity of synechiae but not in improving fertility.

A diagnostic control hysteroscopy is essential to evaluate the uterine cavity, avoid synechiae after any surgery involving the uterine cavity and in the same time to lift possible mucosal synechiae. The practice of early diagnostic hysteroscopy after myomectomy should be systematized to reduce the incidence of traumatic synechiae and preserve fertility. It seems more affordable in our context where non-stick barriers are not available. In addition, intraoperative prevention must always be carried out with meticulous and minimalist gestures in order to avoid any endometrial trauma outside the treated lesion.

\section{Funding: No funding sources}

Conflict of interest: None declared

Ethical approval: The study was approved by the Institutional Ethics Committee

\section{REFERENCES}

1. Wise LA, Palmer JR, Cozier YC, Hunt MO, Stewart E, Rosenberg L. Perceived Racial Discrimination and Risk of Uterine Leiomyomata. Epidemiol 2007;18(6):747-57.

2. Marret H, Fritel X, Ouldamer L, Bendifallah S, Brun JL, De Jesus L et al. Therapeutic management of uterine fibroid tumors: updated french guidelines. Eur J Obstet Gynecol Reprod Biol. 2012;165(2):15664.

3. Valle RF, Sciarra JJ. Intra-uterine adhesions: hysteroscopic diagnosis, classification, treatment and reproductive out-come. Am J Obstet Gynecol. 1988;158(6):1459-70.

4. Yang JH, Chen MJ, Wu MY, Chao KH, Ho HN, Yang YS. Office hysteroscopic early lysis of intrauterine adhesion after transcervical resection of multiple apposing submucous myomas. Fertil Steril. 2008; 89(5):1254-9.

5. Warembourg S, Huberlant S, Garric X, Leprince S, De Tayrac R, Letouzey V. Prevention and treatment of endo-uterine synechia: Literature review. J Gynecol Obstet Biol Reprod. 2015;44(4):366-379.
6. Asherman JG. Amenorrhoea traumatica (atretica). J Obstet Gynaecol Br Emp. 1948;55(1):23-30.

7. Sharma JB, Roy KK, Pushparaj M, Gupta N, Jain SK, Malhotra N. Genital tuberculosis: an important cause of Asherman's syndrome in India. Arch Gynecol Obstet. 2008;277(1):37-41.

8. Schenker JG, Margalioth EJ. Intra-uterine adhesions: an updated appraisal. Fertil Steril 1982;37(5):593605.

9. Munoz JL, Jiménez JS, Hernandez C, Vaquero G, Pérez Sagaseta C, Noguero R. et al., Hysteroscopic myomectomy: our experience and review. JSLS 2003;7(1):39-48.

10. Taskin O, Sadik S, et al. Role of endometrial suppression on the frequency of intrauterine adhesions after resectoscopic surgery. J Am Assoc Gynecol Laparosc. 2000;7(3):351-4.

11. Touboul C, Fernandez H, Deffieux X, Berry R, Frydman R, Gervaise A. Uterine synechiae after bipolar hysteroscopic resection of submocosal myomas in patients with infertility. Fertil Steril 2009; 92(5):1690-3.

12. Fernandez H, Kadoch O, Capella-Allouc S, Gervaise A, Taylor S, Frydman R. Hysteroscopic resection of sub-mucosal myomas: long-term results. Ann Chir 2001;126(7):58-64.

13. Mazzon I, Favilli A, Cocco P, Grasso M, Horvath S, Bini V, et al. Does cold loop hysteroscopic myomectomy reduce intrauterine adhesions? A retrospective study. Fertility and Steril. 2014; 101(1): 294-8.

14. Shokeir TA, Fawzy M, Tatongy M. The nature of intrauterine adhesions following reproductive hysteroscopic surgery as determined by early and late follow-up hysteroscopy: clinical implications. Arch Gynecol Obstet. 2008;277(5):423-7.

15. Deffieux X, Gauthier T, Ménager N, Legendre G, Agostini A, Pierre F. Prevention of complications of hysteroscopy: recommendations for clinical practice. J Gynecol Obstet Biol Reprod 2013;42(8):1032-49.

16. Revaux A, Ducarme G, Luton D. Prevention of synechia after surgical hysteroscopy. Gynecol Obstet Fertil 2008;36:311-317.

17. Frey C, Chanelles O, Poncelet C. Post-operative uterine synechia: what means of prevention? Gynecol Obstet Fertil. 2010;38:550-2.

Cite this article as: Dieme MEF, Niang MM, Gassama O, Diouf AA, Coulibaly MT, Diouf A, et al. Practice of diagnostic hysteroscopy after myomectomy in the prevention of intrauterine adhesions: experience of Ouakam military hospital (Dakar, Senegal). Int J Reprod Contracept Obstet Gynecol 2018;7:1693-8. 